\title{
Efeito da adição de fitase associada a diferentes níveis de proteína bruta e fósforo disponível sobre o desempenho e excreção de proteína bruta de frangos de corte
}

\author{
Andréia Cristina Nakashima \\ VAZ $^{1}$ \\ Ricardo de ALBUQUERQUE ${ }^{1}$ \\ Marcelo Landim BRISOLA ${ }^{2}$ \\ Daniella Carolina Zanardo \\ DONATO $^{1}$ \\ Paula Duarte Silva Rangel \\ GARCIA $^{3}$
}

\section{Correspondência para:}

Andréia Cristina Nakashima Vaz, Rua Coronel Franco, $\mathrm{n}^{\circ} 1591$ - Centro, Pirassununga, SP - CEP 13630136, acnvaz@usp.brou acnvaz@yahoo.com.br

Recebido para publicação: 12/10/2007 Aprovado para publicação: 30/10/2008

\author{
1 - Departamento de Nutrição e Produção Animal da Faculdade de Medicina \\ Veterinária e Zootecnia da Universidade de São Paulo, Pirassununga-SP \\ 2 - Faculdade de Medicina Veterinária da Pontifícia Universidade Católica de Minas \\ Gerais, Poços de Caldas-MG \\ 3 - Médica Veterinária Autônoma
}

\section{Resumo}

Palavras chave: Enzima.

Excretas.

Foram utilizados 504 pintos de linhagem comercial para frangos de Avicultura. corte (Ag Ross 308) de 1 dia de idade, distribuídos em 12 tratamentos com seis repetições. $\mathrm{O}$ delineamento experimental utilizado foi de blocos casualizados em esquema factorial de $2 \times 2 \times 3$, com dois níveis de fósforo disponível (0,45 e 0,34\%), dois níveis de fitase (0 e 1200 FTU/kg) e três níveis de proteína bruta $(22,5 ; 20,5$ e 18,5\%). Houve um aumento do peso das aves que receberam dietas contendo a enzima fitase embora não tenha afetado a conversão alimentar. O consumo não foi afetado pelos níveis de proteína bruta quando ocorreu a suplementação com fitase. A proteína bruta excretada foi reduzida com a suplementação de fitase (33,36 vs. 31,83\%). A enzima Fitase afetou o consumo médio diário e o ganho de peso. Níveis crescentes de proteína bruta na ração ocasionaram maior excreção de proteína bruta, e a suplementação de fitase foi eficiente na redução da proteína bruta excretada.

\section{Introdução}

No Brasil, aproximadamente 90\% das dietas para aves são compostas por ingredientes de origem vegetal (milho e farelo de soja), e a maior parte do fósforo presente nestes componentes apresenta-se sob a forma de ácido fítico. ${ }^{1} \mathrm{~A}$ interação entre o ácido fítico e proteínas parece ser responsável por efeitos nutricionais adversos, visto que, esta interação induz à diminuição da solubilidade das proteínas e, eventualmente, reduz sua utilização. ${ }^{2} \mathrm{Na}$ tentativa de minimizar o custo da criação sem causar danos ao plantel, várias pesquisas têm sido feitas para diminuir a inclusão de proteína na dieta de aves de corte. O presente trabalho teve como objetivo avaliar o efeito da adição da enzima fitase, associada a baixos níveis de fósforo disponível e proteína bruta, sobre o desempenho e excreção de proteína bruta de frangos de corte de 1 a 21 dias de idade.

\section{Material e Método}

O trabalho foi conduzido no aviário experimental do Departamento de Nutrição e Produção Animal da Faculdade de Medicina Veterinária e Zootecnia da Universidade de São Paulo. Foram utilizados 504 pintos de corte, machos, Ag Ross 308, de 1 a 21 dias de idade e peso inicial médio de 42g. As aves foram alojadas em gaiolas de aço inoxidável $(1,0 \mathrm{~m} \times 0,4 \mathrm{~m})$, dispostas em três baterias de seis andares, equipadas com aquecimento elétrico, comedouro, bebedouro tipo "nipple" e bandeja, também de aço inoxidável $(0,9 \mathrm{~m} \times 0,32 \mathrm{~m})$, para colheita de excretas. 
As rações (Tabela 1) foram isonutritivas, exceto para os níveis de proteína bruta e fósforo disponível, à base de milho e farelo de soja, com formulação atendendo os níveis nutricionais recomendados por Rostagno et $\mathrm{al}^{3}{ }^{3}$. As aves receberam água e ração à vontade. As dietas foram calculadas contendo dois níveis de fósforo disponível (0,45 e 0,34\%), dois níveis de fitase (0 e $1200 \mathrm{FTU} / \mathrm{kg}$ ) e três níveis de proteína bruta $(22,5 ; 20,5$ e $18,5 \%)$. A enzima fitase utilizada foi da marca comercial Natuphos ${ }^{\circledR}$ da BASF com atividade de 1200 FTU/kg de ração.

Dos 17 aos 21 dias de idade das aves houve colheita total de excretas, que foram pesadas, identificadas e armazenadas em congelador. Posteriormente, as amostras foram pré-secas a $65^{\circ} \mathrm{C}$, por 72 horas, em estufa de ventilação forçada, moídas e imediatamente preparadas para análise de proteína bruta. ${ }^{4}$
O delineamento experimental utilizado foi de blocos casualizados, em esquema fatorial $2 \times 2 \times 3$, com seis repetições e sete aves por unidade experimental. Os dados foram submetidos à análise de variância e, a partir desta análise, foram realizados testes de regressão entre os níveis de proteína bruta e as variáveis, respeitando a presença ou não das interações. O programa estatístico utilizado foi o Statistical Analisys System. ${ }^{5}$

\section{Resultados}

Houve diferença significativa entre as médias de consumo diário (0 e 1200 FTU/kg de fitase, com consumo de 46,21 e $49,64 \mathrm{~g} /$ dia, respectivamente), quando as aves receberam uma dieta contendo $22,5 \%$ de proteína bruta. Houve redução no consumo de ração com o aumento de proteína bruta (efeito linear, $\mathrm{P}<0,05$ ) na ausência de fitase (Tabela 2). Os tratamentos com um nível de

Tabela 1 - Composição bromatológica calculada (\%) das dietas experimentais

\begin{tabular}{|c|c|c|c|c|c|c|c|c|c|c|c|c|}
\hline \multirow[t]{4}{*}{ Alimento } & \multicolumn{12}{|c|}{ Ração (PB/Pd) } \\
\hline & A & B & $\mathrm{C}$ & D & E & $\mathrm{F}$ & $\mathrm{G}$ & $\mathrm{H}$ & I & $\mathrm{J}$ & $\mathrm{K}$ & L \\
\hline & \multicolumn{3}{|c|}{+ fitase } & + fitase & \multicolumn{3}{|c|}{ - fitase } & +fitase & \multicolumn{3}{|c|}{ + fitase } & \multirow{3}{*}{$\begin{array}{c}\text {-fitase } \\
\frac{18,5 / 0,34}{2950}\end{array}$} \\
\hline & $22,5 / 0,45$ & $22,5 / 0,45$ & $20,5 / 0,45$ & $20,5 / 0,45$ & $18,5 / 0,45$ & $18,5 / 0,45$ & $22,5 / 0,34$ & $22,5 / 0,34$ & $20,5 / 0,34$ & $20,5 / 0,34$ & $18,5 / 0,34$ & \\
\hline EM (kcal/kg) & 2950 & 2950 & 2950 & 2950 & 2950 & 2950 & 2950 & 2950 & 2950 & 2950 & 2950 & \\
\hline PB (\%) & 22,50 & 22,50 & 20,50 & 20,50 & 18,52 & 18,52 & 22,5 & 22,5 & 20,50 & 20,50 & 18,57 & 18,57 \\
\hline $\mathrm{Ca}(\%)$ & 0,95 & 0,95 & 0,95 & 0,95 & 0,95 & 0,95 & 0,95 & 0,95 & 0,95 & 0,95 & 0,95 & 0,95 \\
\hline $\operatorname{Pd}(\%)$ & 0,45 & 0,45 & 0,45 & 0,45 & 0,45 & 0,45 & 0,34 & 0,34 & 0,34 & 0,34 & 0,34 & 0,34 \\
\hline Lis $(\%)$ & 1,124 & 1,124 & 1,056 & 1,056 & 1,056 & 1,056 & 1,122 & 1,122 & 1,056 & 1,056 & 1,056 & 1,056 \\
\hline Metionina (\%) & 0,447 & 0,44 & 0,458 & 0,458 & 0,524 & 0,52 & 0,447 & 0,447 & 0,484 & 0,484 & 0,519 & 0,519 \\
\hline Met+cis (\%) & 0,710 & 0,71 & 0,710 & 0,710 & 0,710 & 0,710 & 0,710 & 0,710 & 0,710 & 0,710 & 0,710 & 0,710 \\
\hline Triptofano (\%) & 0,254 & 0,25 & 0,225 & 0,225 & 0,196 & 0,196 & 0,254 & 0,254 & 0,225 & 0,225 & 0,199 & 0,199 \\
\hline Treonina (\%) & 0,768 & 0,76 & 0,694 & 0,694 & 0,661 & 0,66 & 0,768 & 0,768 & 0,694 & 0,694 & 0,661 & 0,661 \\
\hline $\begin{array}{l}\text { Suplementaçã } \\
\text { Suplemento v } \\
\text { biotina, } 0,02 \mathrm{r}\end{array}$ & $\begin{array}{l}\text { de fitase: } 0 \\
\text { aminico fo } \\
\text {;; selênio, }\end{array}$ & & $\begin{array}{l}\text { etas A, C, E, G, I } \\
\text { kg de dieta: vitar } \\
\text { ntioxidante, } 30 \mathrm{~m}\end{array}$ & $\begin{array}{l}\text { K) e } 1200 \mathrm{FT} \\
\text { nina } A, 10000 \\
\text { g }\end{array}$ & $\begin{array}{l}\text { U (dietas B } \\
\text { U; vitamir }\end{array}$ & $\begin{array}{l}, \mathrm{F}, \mathrm{H}, \\
03,200\end{array}$ & $\begin{array}{l}\mathrm{J}, \mathrm{L}) \text {; } \\
0 \mathrm{UI} \text {, vitamina }\end{array}$ & $0 \mathrm{mg}$; vitami & $\mathrm{K} 3,2 \mathrm{~m}$ & iamins & $\mathrm{mg}$; ribofla & $5 \mathrm{mg}$ \\
\hline Tabela 2 - & $\begin{array}{l}\text { dos d } \\
\text { le pro }\end{array}$ & & $\begin{array}{l}\text { mpenho (ce } \\
\text { ruta }\end{array}$ & onsumo d & le raçãc & ga & ho de pe & por ní & eis de & ase, & fósforo & sponível \\
\hline Consumo de r & âo, em grar & as porc & iia (média \pm desv & io padrăo), po & r niveis de & ase, de & fósforo e de prot & eima & & & & \\
\hline & & & & & Fitase & & & & & & & Média \\
\hline Niveis & & & 0 & & & & 1200 & & & & & geral por \\
\hline $\begin{array}{c}\text { de } \\
\text { proteina }\end{array}$ & & Fós & $\begin{array}{r}\text { foro } \\
0,45\end{array}$ & $\begin{array}{l}\text { Média } \\
0 \text { fitase }\end{array}$ & & Föst & 0,45 & $\begin{array}{c}\text { Média } \\
1200 \text { fitase }\end{array}$ & & Fósf & ore & $\begin{array}{l}\text { nivel de } \\
\text { proteina }\end{array}$ \\
\hline 18,5 & 48,8 & $=1,57$ & $49,02=2,02$ & $48,94 \pm 1,73$ & $49,0 \mathrm{C}$ & $=1,29$ & $47,34 \pm 3,71$ & $48,17 \pm 2,79$ & 48,9 & $3 \pm 1,37$ & $48,18=2,98$ & $48,56=2,30$ \\
\hline 20,5 & 44,9 & $=2,65$ & $48,55 \pm 1,84$ & $46,74 \pm 2,89$ & 47,1 & $=3,47$ & $48,99=1,12$ & $48,07 \pm 2,64$ & 46,0 & $4 \pm 3,17$ & $48,77 \pm 1,47$ & $47,41 \pm 2,79$ \\
\hline 22,5 & 45,5 & $=1,44$ & $46,87 \pm 1,23$ & $46,21^{3}=1,45$ & 50,0 & $=6,22$ & $49,42=3,14$ & $49,64^{b} \pm 3,99$ & 47,0 & $5 \pm 4,01$ & $48,15 \pm 2,63$ & $47,68 \pm 2,25$ \\
\hline & & & & $47,30 \pm 2,38$ & & & & $48,53 \pm 3,08$ & 47,3 & $7 \pm 3,12$ & $48,37 \pm 2,39$ & \\
\hline ho de pesc & amas pc & $\operatorname{dia}(\mathrm{m}$ & edia \pm desvio $p$ ac & (iza)), por ni & de fitase, & le fósfor & ro e de protéma & & & & & \\
\hline 18,5 & 35,1 & $\pm 1,25$ & $34,93 \pm 1,55$ & $35,03 \pm 1,34$ & 35,5 & $\pm 0,98$ & $34,46 \pm 1,52$ & $35,00 \pm 1,35$ & 35,3 & $3 \pm 1,09$ & $34,70 \pm 1,48$ & $35,02 \pm 1,32$ \\
\hline 20,5 & 32,5 & $=1,94$ & $36,69=1,02$ & $34,63^{a}=2,60$ & 34,6 & $\pm 2,37$ & $36,80=0,73$ & $35,70^{\circ}=2,03$ & 33,5 & $9=2,32$ & $36,75=0,85$ & $35,17 \pm 2,35$ \\
\hline 22,5 & 34,8 & $=1,16$ & $35,49=2,03$ & $35,17 \pm 1,61$ & 34,6 & $=3,08$ & $36,12=1,25$ & $35,64=1,97$ & 34,7 & $9=1,79$ & $35,81=1,64$ & $35,37 \pm 1,74$ \\
\hline & & & & $34,94 \pm 1,89$ & & & & $35,43 \pm 1,76$ & & $5 \pm 1,91$ & $35,75 \pm 1,58$ & \\
\hline
\end{tabular}

Médias na linha com letras diferentes diferem significativamente ( $P<0,05)$, pela análise de varância. Os resultados da análise de regressão são apresentados no texto 
proteína bruta igual a 20,5\%, apresentaram diferença significativa $(\mathrm{P}<0,05 \%)$, independente do nível de fósforo disponível. A média geral, para ganho de peso, foi de 34,63 e $35,70 \mathrm{~g} / \mathrm{dia}$ com 0 e $1200 \mathrm{FTU} / \mathrm{kg}$ de fitase, respectivamente. Neste nível de proteína bruta, a fitase apresentou efeito $(\mathrm{P}<0,05)$ no ganho de peso. Ocorreram efeitos quadráticos em relação aos níveis de proteína bruta, diferentes para cada nível de fósforo disponível ( 0,34 e $0,45 \%$ ), sendo que houve menor ganho de peso das aves que receberam $20,5 \%$ de proteína bruta em relação àquelas que receberam $18,5 \%$ ou $22,5 \%$ de proteína bruta na dieta com $0,34 \%$ de fósforo disponível, e o oposto com $0,45 \%$ de fósforo disponível (Tabela 2). Não foi observado nenhum efeito significativo na conversão alimentar das aves (Tabela 3). Os valores de proteína bruta nas excretas (\%) são apresentados na tabela 3. A porcentagem de proteína bruta nas excretas aumentou (efeito linear, $\mathrm{P}<0,05)$ conforme o aumento do nível de proteína bruta incluída na dieta, a suplementação de fitase reduziu a quantidade de proteína bruta nas excretas $(\mathrm{P}<0,05)$.

\section{Discussão}

O consumo médio não diferiu significativamente quanto à adição de fitase e fósforo disponível nos níveis de proteína bruta de 18,5 e 20,5\%, o que está de acordo com Costa et al. ${ }^{6}$, que também não verificaram efeito da fitase no consumo de rações formuladas à base de milho e farelo de soja com $23 \%$ de proteína bruta (fase pré-inicial - 1 a 7 dias de idade) e $21 \%$ de proteína bruta (fase inicial -8 a 21 dias de crescimento) nas dietas. Estes resultados diferem dos resultados encontrados por Broz et al. ${ }^{7}$ que, estudando os efeitos da inclusão de diferentes níveis de fitase microbiana em rações para aves com baixo nível de fósforo disponível $(0,45 \%$ de fósforo total), observaram um aumento significativo no consumo de ração do $8^{\circ}$ ao $22^{\circ}$ dia de idade com o aumento dos níveis de fitase. No presente trabalho, somente com o nível de $22,5 \%$ de proteína bruta na dieta houve aumento significativo no consumo de ração com a presença da enzima.

As médias gerais de ganho de peso, para as aves com e sem fitase na dieta $(0$ e 1200 FTU $/ \mathrm{kg}$ ) foram, respectivamente, 34,94 e 35,43 g/dia, não apresentando diferença significativa. Resultados semelhantes foram obtidos por Yu et al. ${ }^{8}$ ao estudarem a atividade gastrointestinal da fitase em frangos de corte. Resultados contrários foram verificados por Ahmad et al. ${ }^{9}$. Estes observaram um aumento de $2,65 \%$ no peso corporal das aves comparado àquelas que receberam uma dieta que não continha a enzima fitase. Sebastian et $\mathrm{al}^{2}$ também observaram melhora no ganho de peso de aves alimentadas com rações suplementadas com fitase.

No presente estudo, a fitase não mostrou efeitos significativos na conversão alimentar de aves. O mesmo foi observado

Tabela 3 - Proteína bruta excretada e conversão alimentar por níveis de fitase, de fósforo disponível e de proteína bruta

\begin{tabular}{|c|c|c|c|c|c|c|c|c|c|}
\hline \multicolumn{10}{|c|}{ Porcentagem de proteina bruta das excretas (média = desvio padrão), por niveis de fitase, de fósforo e de proteina } \\
\hline 18,5 & $29,20=2,45$ & $29,60=4,27$ & $29,40 \pm 3,33$ & $27,58 \pm 0,85$ & $28,44 \pm 1,31$ & $28,01=1,15$ & $28,39=1,94$ & $29,02=3,07$ & $28,71=2,53$ \\
\hline 20,5 & $32,84 \pm 1,68$ & $33,15 \pm 2,87$ & $33,00 \pm 2,25$ & $32,38 \pm 1,62$ & $32,77 \pm 2,44$ & $32,58 \pm 1,99$ & $32,61 \pm 1,59$ & $32,96 \pm 2,55$ & $32,79 \pm 2,09$ \\
\hline \multirow[t]{2}{*}{22,5} & $38,89 \pm 1,52$ & $36,44 \pm 1,62$ & $37,67 \pm 1,97$ & $37,48 \pm 1,03$ & $35,13 \pm 4,18$ & $35,91 \pm 3,54$ & $38,42 \pm 1,48$ & $35,78 \pm 3,10$ & $36,91 \pm 2,82$ \\
\hline & & & \multicolumn{3}{|l|}{$33,36^{2} \pm 4,25$} & $31,83^{b} \pm 3,91$ & $32,66 \pm 4,35$ & \multicolumn{2}{|l|}{$32,59 \pm 3,99$} \\
\hline 18,5 & $1,39 \pm 0,02$ & $1.41 \pm 0.12$ & $140 \pm 0.08$ & $1,38 \pm 0,03$ & $1,38 \pm 0,13$ & $1,38 \pm 0.09$ & $138 \pm 0,03$ & $139 \pm 0.12$ & $1,39 \pm 0,09$ \\
\hline 20,5 & $1,38=0,08$ & $1,32 \pm 0,03$ & $1,35 \pm 0,07$ & $1,36=0,08$ & $1,33=0,03$ & $1,35 \pm 0,06$ & $1,37 \pm 0,08$ & $1,33 \pm 0,03$ & $1,35=0,06$ \\
\hline \multirow[t]{2}{*}{22,5} & $1,31=0,04$ & $1,32=0,09$ & $1,32 \pm 0,07$ & $1,46=0,32$ & $1,37 \pm 0,08$ & $1,40 \pm 0,18$ & $1,36 \pm 0,18$ & $1,35=0,09$ & $1,35=0,13$ \\
\hline & & & $1,36 \pm 0,08$ & & & $1,37 \pm 0,11$ & $1,37 \pm 0,10$ & $1,35=0,09$ & \\
\hline
\end{tabular}

Médias na linha com letras diferentes diferem significativamente $(P<0,05)$, pela análise de varância

Os resultados da análise de regres são são apresenta dos no texto. 
por Silva et al. ${ }^{10}$ e Johnston e Southern ${ }^{11}$. No entanto, vários pesquisadores observaram efeitos contrários. ${ }^{1,12,13}$

Houve efeito linear entre as porcentagens de proteína bruta excretada de acordo com os níveis crescentes de proteína bruta incluídas na dieta, como observado por Silva et al. ${ }^{10}$. Tejedor et al. ${ }^{4}$, trabalhando com níveis normais de cálcio e fósforo disponível (1 e 0,45\%, respectivamente) e níveis baixos $(0,70 \%$ de cálcio e $0,32 \%$ de fósforo disponível), acrescidos ou não de fitase, observaram um aumento nos coeficientes de digestibilidade de proteína bruta, cálcio, fósforo e energia bruta, pela adição da fitase, independente do tratamento. No presente trabalho houve redução significativa na porcentagem de proteína bruta nas excretas (33,36 vs. $31,83 \%)$ com o uso da enzima. Entretanto, Sebastian et al. ${ }^{2}$ não observaram efeito da suplementação de fitase na digestibilidade aparente de proteína bruta ou aminoácidos, excepcionalmente para metionina e fenilalanina, em frangos de corte machos.

\section{Conclusão}

A enzima fitase depende dos níveis de fósforo disponível e proteína bruta para atuar no organismo animal. A enzima afetou o consumo médio diário e o ganho de peso, dependendo do nível de proteína bruta da dieta. Níveis crescentes de proteína bruta na ração ocasionaram maior excreção de proteína bruta, e a suplementação de fitase foi eficiente na redução de proteína bruta excretada.

\section{Agradecimentos}

À Fundação de Apoio à Pesquisa do Estado de São Paulo - FAPESP, TORTUGA e BASF pelo apoio.

\title{
Effect of phytase supplementation with different levels of crude protein and available phosphorum on performance and crude protein excretion of broiler chickens
}

\begin{abstract}
It was used 504 (five hundred four) 1 day old male chicks, of a commercial broiler line (Ag Ross 308), distributed in 12 treatments, with 6 replicates per treatment. The experimental design was casually blocked and treatments were organized in a $2 \times 2 \times 3$ factorial arrangement: two phosphorus levels ( 0.45 and $0.34 \%$ ), two phytase inclusion levels ( 0 and $1200 \mathrm{FTU} / \mathrm{kg}$ ) and three protein levels $(22.5$; 20.5 and $18.5 \%$ ). Body weight gain was observed in birds fed diets with phytase supplementation although it hasn't affected the feed conversion ratio. Feed intake wasn't affected by the low protein levels with added phytase. Crude protein excreted was lower with phytase supplementation (33.36 vs $31.83 \%$ ). Phytase enzyme affected dairy feed intake and body weight gain. Crude protein crescent levels on diet caused increased crude protein excretion, and phytase supplementation was efficient reducing crude protein excreted.
\end{abstract}

Key words: Enzyme. Faeces. Aviculture. Performance. Crude protein.

\section{Referências}

1 TEJEDOR, A. A.; ALBINO, L. F. T.; ROSTAGNO, H. S.; LIMA, C. A. R.; VIEITES, F. M. Efeito da adição de enzimas em dietas de frangos de corte à base de milho e farelo de soja sobre a digestibilidade ileal de nutrientes. Revista Brasileira de Zootecnia, v. 30, n. 3, p. 809-
816, 2001.

2 SEBASTIAN, S.; TOUCHBURN, S. P.; CHAVEZ, E. R.; LAGUE, P. C. Apparent digestibility of protein anda mino acids in broiler chickens fed a corn-soybean diet supplemented with microbial phytase. Poultry Science, v. 76, n. 12, p. 1760-1769, 1997.

3 ROSTAGNO, H. S. et al. Tabelas brasileiras para aves 
e suínos: composição de alimentos e exigências nutricionais. Viçosa: Horácio Rostagno, 2000. 141 p.

4 TEJEDOR, A. A.; ALBINO, L. F. T.; ROSTAGNO, H. S.; VIEITES, F. M. Efeito da adição da enzima fitase sobre o desempenho e a digestibilidade ileal de nutrientes. Revista Brasileira de Zootecnia, v. 30, n. 3, p. 802-808, 2001.

5 STATISTICAL ANALISYS SYSTEM. SAS user's guide: Statistics. Versão 6. Cary: SAS Institute, 1996.

6 COSTA, F. G. P.; BRANDÃO, P. A.; BRANDÃO, J. S.; SILVA, J. H. V. Efeito da enzima fitase nas rações de frangos de corte, durante as fases pré-inicial e inicial. Ciência Agrotécnica, v. 31, n. 3, p. 865-870, 2007.

7 BROZ, J.; OLDALE, P.; PERRIN-VOLTZ, A-H ; RYCHEN, G.; SCHULZE, J.; SIMÕES NUNES, C. Effect of supplemental phytase on performance and phosphorus utilization in broiler chickens fed a low phosphorus diet without addition of inorganic phosphates. British Poultry Science, v. 35, n. 2, p. 273280, 1994.

8 YU, B.; JAN, Y.; CHUNG, T.; LEE, T.; CHIOU, P. Exogenous phytase activity in the gastrointestinal tract of broiler chickens. Animal Feed Science and Technology, v. 117, n. 3/4, p. 295-303, 2004.

9 AHMAD, T.; RASOOL, S.; SARWAR, M.; HAQ, A.;
HSAN, Z. Effect of microbial phytase produced from a fungus Aspergillus niger on bioavailability of phosphorus and calcium in broiler chickens. Animal Feed Science and Technology, v. 83, n. 2, p. 103-114, 1999.

10 SILVA, Y. L.; RODRIGUES, P. B.; FREITAS, R. T. F.; BERTECHINI, A. G.; FIALHO, E. T.; FASSANI, E. J.; PEREIRA, C. R. Redução de proteína e fósforo em rações com fitase para frangos de corte no período de 1 a 21 dias de idade: desempenho e teores de minerais na cama. Revista Brasileira de Zootecnia, v. 35, n. 3, p. 840-848, 2006.

11 JOHNSTON, S. L.; SOUTHERN, L. L. The effect of varying mix uniformity (simulated) of phytase on growth performance, mineral retention, and bone mineralization in chicks. Poultry Science, v. 79, n. 10, p. 1485-1490, 2000.

12 ROCHA, P. T.; STRINGHINI, J. H.; ANDRADE, M. A.; LEANDRO, N. S. M.; ANDRADE, M. L.; CAFÉ, M. B. Desempenho de frangos de corte alimentados com rações pré-iniciais contendo diferentes níveis de proteína bruta e energia metabolizável. Revista Brasileira de Zootecnia, v. 32, n. 1, p. 162-170, 2003.

13 RUNHO, R. C.; GOMES, P. C.; ROSTAGNO, H. S.; ALBINO, L. F. T.; LOPES, P. S.; POZZA, P. C. Exigências de fósforo disponível para frangos de corte machos e fêmeas de 1 a 21 dias de idade. Revista Brasileira de Zootecnia, v. 30, n. 1, p. 187-196, 2001. 